\title{
A case of polypoidal choroidal vasculopathy. Periphery is equally important for such patients
}

This article was published in the following Dove Press journal:

Clinical Interventions in Aging

25 June 2009

Number of times this article has been viewed

\section{Dimitrios A Karagiannis \\ Vasilios Soublis \\ Artemios Kandarakis \\ Ist Ophthalmology Department of Ophthalmiatrio Eye Hospital of Athens, Athens, Greece}

Correspondence: Dimitrios A Karagiannis 5 Dimokratias Ave,

Drosia 14572, Athens, Greece

Tel +30210 621 0043

$\mathrm{Fax}+302103235526$

Email dimitrioskaragiannis@doctors.org.uk
Background: To report a case of peripheral polypoidal choroidal vasculopathy (PCV) which was treated successfully.

Methods: Interventional case report. Best-corrected visual acuity measurements (BCVA), slit-lamp examination, fundus biomicroscopy, fluorescein angiography (FFA), and indocyanine green angiography (ICGA) were performed at baseline examination and during the follow-up period. The patient underwent ICGA-guided argon laser to treat the active polyps.

Results: An 82-year-old Caucasian man presented complaining of sudden deterioration of peripheral vision in his left eye (LE). His previous ocular history was associated with advanced age-related macular degeneration (AMD) involving both eyes (BE). Fundus examination revealed macular scars in BE and a large hemorrhagic pigment epithelial detachment (PED) temporal to the macula in the LE. ICGA revealed active polyps at the margins of the PED. The patient underwent ICGA-guided argon laser to treat the active polyps. Six months post-laser, the patient regained his peripheral vision with resolution of the hemorrhagic PED and remains stable until now, one year after treatment.

Conclusions: Appropriate treatment and regular follow-up is important in patients with PCV and peripheral lesions even if central vision is lost.

Keywords: argon laser, peripheral vision, polypoidal choroidal vasculopathy

\section{Introduction}

Idiopathic polypoidal choroidal vasculopathy (PCV) is an exudative disorder of the macula. Although its pathogenesis remains unclear, it is generally thought to be an inner choroidal vascular abnormality ${ }^{1}$ which usually emanates from the posterior pole ${ }^{1}$ or less commonly from the peripheral retina. ${ }^{2}$ We report a case of PCV in the peripheral fundus in a patient with bilateral end-stage age-related macular degeneration (AMD) treated successfully.

\section{Case presentation}

An 82-year-old Caucasian man presented in our department complaining of sudden deterioration of peripheral vision in his left eye (LE). His previous ocular history was associated with advanced AMD involving both eyes. Best-corrected visual acuity (BCVA) was counting fingers in both eyes. The anterior segments and intraocular pressures were within normal limits in both eyes. Fundus examination revealed scar formation involving the center of the fovea bilaterally. In addition, a large hemorrhagic pigment epithelial detachment (PED) was detected temporal to the macula in the LE 


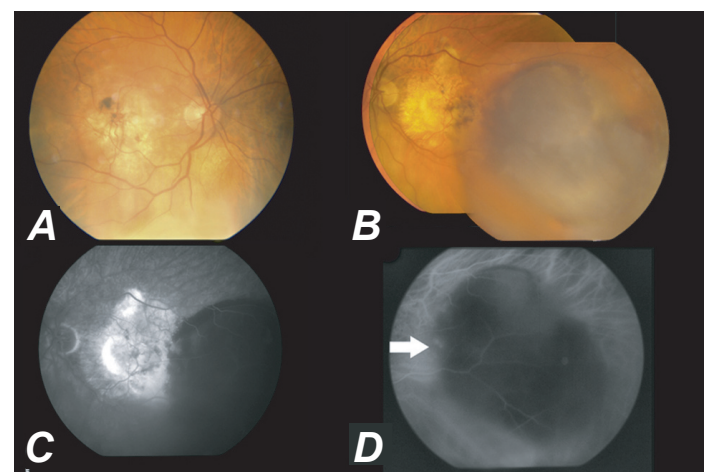

Figure I A) Color fundus picture of the right eye of our patient showing a macular scar. B) Color-mosaic fundus picture of the left eye (LE) before treatment showing a macular scar and a large hemorrhagic pigment epithelial detachment (PED) temporal to the fovea resembling a choroidal melanoma. C) Late phase of fluorescein angiography of the LE showing hyperfluorescence due to staining of fibrotic tissue at the fovea and hypofluorescence due to masking of the hemorrhagic PED temporal to the fovea. D) Mid phase of Indocyanine green angiography showing hypofluorescence due to the PED with two hot spots at the margins (white arrows).

Abbreviation: PED, pigment epithelial detachment.

Indocyanine green angiography (ICGA) disclosed the presence of actively leaking polypoidal vessels at the margins of the PED. The diagnosis of peripheral idiopathic PCV in a patient with advance AMD was made. After informed consent was obtained, ICGA-guided argon laser photocoagulation was applied. Six months post-laser, the hemorrhagic PED was resolved. One year later, the patient remains stable and his peripheral vision has significantly improved.

\section{Discussion}

In 1990, idiopathic PCV was first described by Yannuzzi and colleagues ${ }^{1}$ as a vascular disorder originating from the choroidal circulation. This disorder has been recognized increasingly in recent years as a distinct clinical entity separate from AMD. The pathogenesis of PCV remains unclear. Recent genetic research has shown that PCV and AMD share common genetic factors ${ }^{3}$ which may suggest that although PCV and wet AMD have different clinical characteristics, they may share same similar pathophysiologic aspects. In support of the latter, Lafaut and colleagues ${ }^{4}$ reported the possible coexistence of AMD and PCV in the same patient histopathologically.

Patients with end-stage AMD, characterized from the development of fibrotic tissue in the fovea, experience a significant loss of central vision. Peripheral retina is rarely affected allowing the patient to maintain some quality in their peripheral or side vision. Modifying the patient's environment and using available low vision devices and aids, AMD patients can continue to maintain their lifestyle and independence.

Choroidal vascular lesions of PCV are more preferable found in the posterior pole of the retina, ${ }^{4}$ although further evidence suggests that the lesion could also be found in the peripheral retina up to $63 \% .3,5$

We report a case of peripheral PCV in a male patient with advanced bilateral AMD affecting severely both foveal areas. The initial complain of the patient was deterioration of peripheral vision in addition to the already affected central vision. Such a clinical situation may impair significantly the quality of life of the patient and needs to be promptly identified, diagnosed and treated in order to preserve, in the best possible way, the peripheral vision of the patient.

Currently there are many therapeutics options for PCV. Photodynamic therapy alone or combined with anti-vascular endothelial growth factor treatment showed promising results. ${ }^{6}$ However, use of a conventional argon laser achieved up to $78 \%$ clinical or angiographic resolution of maculopathy for extrafoveal polyps. ${ }^{7}$ When PCV lesions accompany PED, the lesions are usually located at the margins of PED ${ }^{8}$ In our case, ICGA-guided argon laser photocoagulation was selected, since central vision was impaired due to foveal scars and the polyp lesions were extrafoveal and at the margins of the PED.

In our case, treatment with ICGA-guided argon laser photocoagulation was beneficial and resolved the hemorrhagic PED, preserving the peripheral vision of the patient. Appropriate treatment and regular follow-up is important in patients with PCV even if central vision is lost.

\section{Disclosure}

The authors report no conflicts of interest or financial support in this work.

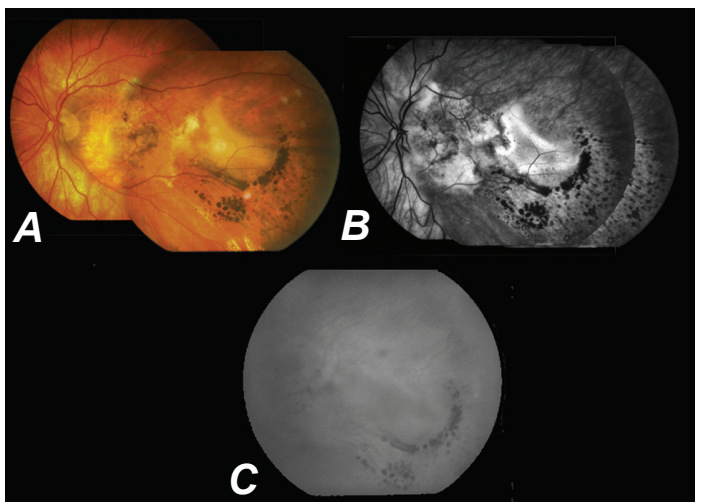

Figure 2 A) Color-mosaic fundus picture of the left eye (LE) six months post-ICGA-guided argon laser showing a macular scar and almost complete resolution of the hemorrhagic pigment epithelial detachment (PED) temporal to the fovea. The appearance remained stable for another six months. B) Late phase of FFA of the LE resolution of the PED temporal to the fovea with hyperfluorescence due to staining of the fibrotic tissue. C) Late phase of ICGA at the same time showing the area corresponding to the PED with no active hot spots.

Abbreviations: FFA, fluorescein angiography; ICG, indocyanine green angiography; PED, pigment epithelial detachment. 


\section{References}

1. Yannuzzi LA, Sorenson J, Spaide RF, Lipson B. Idiopathic polypoidal choroidal vasculopathy (IPCV). Retina. 1990;10:1-8.

2. Yannuzzi LA, Nogueira FB, Spaide RF, et al. Idiopathic polypoidal choroidal vasculopathy: a peripheral lesion. Arch Ophthalmol. 1998;116(3):382-383.

3. Kondo N, Honda S, Ishibashi K, Tsukahara Y, Negi A. LOC387715/ HTRA1 variants in polypoidal choroidal vasculopathy and age-related macular degeneration in a Japanese population. Am J Ophthalmol. 2007;144(4):608-612.

4. Lafaut BA, Aisenbrey S, Van den Broecke C, Bartz-Schmidt KU, Heimann K. Polypoidal choroidal vasculopathy pattern in age-related macular degeneration: a clinicopathologic correlation. Retina. 2000;20(6):650-654.
5. Cackett P, Wong D, Yeo I. A classification system for polypoidal choroidal vasculopathy. Retina. 2009;29(2):187-191.

6. Gomi F, Tano Y. Polypoidal choroidal vasculopthy and treatments. Curr Opin Ophthalmol. 2008;19(3):208-212.

7. Lee MW, Yeo I, Wong D, Ang CL. Argon laser photocoagulation for the treatment of polypoidal choroidal vasculopathy. Eye. 2009;23(1): $145-148$.

8. Tsujikawa A, Sasahara M, Otani A, et al. Pigment epithelial detachment in polypoidal choroidal vasculopathy. Am J Ophthalmol. 2007;143(1):102-111.
Clinical Interventions in Aging

\section{Publish your work in this journal}

Clinical Interventions in Aging is an international, peer-reviewed journal focusing on evidence-based reports on the value or lack thereof of treatments intended to prevent or delay the onset of maladaptive correlates of aging in human beings. This journal is indexed on PubMed Central, MedLine, the American Chemical Society's 'Chemical

\section{Dovepress}

Abstracts Service' (CAS), Scopus and the Elsevier Bibliographic databases. The manuscript management system is completely online and includes a very quick and fair peer-review system, which is all easy to use. Visit http://www.dovepress.com/testimonials.php to read real quotes from published authors.

Submit your manuscript here: http://www.dovepress.com/clinical-interventions-in-aging-journal 